\title{
"Harnessing genomics to improve health in India" - an executive course to support genomics policy
} Tara Acharya ${ }^{1}$, Nandini K Kumar ${ }^{2}$, Vasantha Muthuswamy², Abdallah S Daar ${ }^{1}$ and Peter A Singer*1

\author{
Address: ${ }^{1}$ Joint Center for Bioethics, University of Toronto, 88 College Street, Toronto, ON - M5G 1L4, Canada and ${ }^{2}$ Indian Council of Medical \\ Research, Ansari Nagar, New Delhi 110 029, India \\ Email: Tara Acharya - tara.acharya@utoronto.ca; Nandini K Kumar - kumarn@icmr.delhi.nic.in; \\ Vasantha Muthuswamy - muthuswamyv@icmr.delhi.nic.in; Abdallah S Daar - a.daar@utoronto.ca; Peter A Singer* - peter.singer@utoronto.ca \\ * Corresponding author
}

Published: 19 May 2004

Health Research Policy and Systems 2004, 2:1
Received: 14 October 2003

Accepted: 19 May 2004

This article is available from: http://www.health-policy-systems.com/content/2/1/I

(C) 2004 Acharya et al; licensee BioMed Central Ltd. This is an Open Access article: verbatim copying and redistribution of this article are permitted in all media for any purpose, provided this notice is preserved along with the article's original URL.

\begin{abstract}
Background: The benefits of scientific medicine have eluded millions in developing countries and the genomics revolution threatens to increase health inequities between North and South. India, as a developing yet also industrialized country, is uniquely positioned to pioneer science policy innovations to narrow the genomics divide. Recognizing this, the Indian Council of Medical Research and the University of Toronto Joint Centre for Bioethics conducted a Genomics Policy Executive Course in January 2003 in Kerala, India. The course provided a forum for stakeholders to discuss the relevance of genomics for health in India. This article presents the course findings and recommendations formulated by the participants for genomics policy in India.

Methods: The course goals were to familiarize participants with the implications of genomics for health in India; analyze and debate policy and ethical issues; and develop a multi-sectoral opinion leaders' network to share perspectives. To achieve these goals, the course brought together representatives of academic research centres, biotechnology companies, regulatory bodies, media, voluntary, and legal organizations to engage in discussion. Topics included scientific advances in genomics, followed by innovations in business models, public sector perspectives, ethics, legal issues and national innovation systems.

Results: Seven main recommendations emerged: increase funding for healthcare research with appropriate emphasis on genomics; leverage India's assets such as traditional knowledge and genomic diversity in consultation with knowledge-holders; prioritize strategic entry points for India; improve industry-academic interface with appropriate incentives to improve public health and the nation's wealth; develop independent, accountable, transparent regulatory systems to ensure that ethical, legal and social issues are addressed for a single entry, smart and effective system; engage the public and ensure broadbased input into policy setting; ensure equitable access of poor to genomics products and services; deliver knowledge, products and services for public health. A key outcome of the course was the internet-based opinion leaders' network - the Indian Genome Policy Forum - a multi-stakeholder forum to foster further discussion on policy.
\end{abstract}

Conclusion: We expect that the process that has led to this network will serve as a model to establish similar Science and Technology policy networks on regional levels and eventually on a global level. 


\section{Background}

Over the last hundred years, innovations in medicine, science and technology have resulted in improved health, quality of life and a rise in life expectancy worldwide. In light of this impressive record it is disheartening that the benefits of scientific medicine continue to elude millions of people in the poorer parts of the world [1]. Children and adults are undernourished, live in poor housing and die from illnesses that are often preventable in the prime of their lives. India, with its wealth of scientific researchers and medical professionals, has made impressive gains in scientific medicine, but the health needs of the majority of the population continue to be unmet.

India is a developing country with a population of over 1 billion, the majority of which live in poverty and have little access to modern medicine. On the other hand, it is counted among the most industrialized countries in the world, with the largest pool of English-speaking scientific and technical professionals outside the United States. It has a well-established pharmaceutical industry. It also continues to be the world leader in the information technology sector, which has spawned a burgeoning bioinformatics industry. In fact, India's success in information technology - its computer software and services industry grew from about $\$ 500$ million to more than $\$ 6$ billion in exports over the last decade - may provide a model for its biotechnology aspirations [2]. However, it can be argued that building biotechnology capability will be a more challenging task. In order to achieve its biotech potential, India will have to overcome some significant challenges, including uncharted territory in regulatory issues, an evolving intellectual property rights environment, and the slow pace of integration between academic and private sector science. Despite these hurdles, India has made impressive forays into the biotechnology sector, both through public sector efforts as well as industry innovation.

In order to assess the potential of these advances to address health needs in India, the Indian Council of Medical Research and Joint Centre for Bioethics at the University of Toronto jointly organized a Genomics Policy Executive Course, from January $20^{\text {th }}-23^{\text {rd }}, 2003$, at Kumarakom Lake Resort in Kerala, India. This 4-day course was conducted by the Indian Council of Medical Research and University of Toronto's Joint Centre for Bioethics, and sponsored by ICMR, Genome Canada, and the International Development Research Centre. The primary goal of the course was to familiarize participants with the potential of genomics and related biotechnologies to address health needs in India and to collectively address the question of how to best harness genomics to improve health (Figure 1).

\section{Methods}

The program was planned by first preparing a schedule with presentation topics. We based the layout of the sessions and lecture topics on prior courses held in Nairobi, Kenya in March 2002 and in Toronto, Canada in May 2002. The sessions and presenters are shown in Table 1.

- To familiarize participants with the current status and implications of genomics and biotechnology for health in India, and to provide information relevant to public policy

- To provide frameworks for analyzing and debating the policy issues and related ethical questions, and to help understand, anticipate and possibly influence the legal and regulatory frameworks which will operate, both nationally and internationally

- To begin developing an opinion leaders' network across different sectors (industry, academic, government, and voluntary organisations) by sharing perspectives and building relationships

\section{Figure I}

Objectives of the Course 
Table I: Program and Session Facilitators

\begin{tabular}{|c|c|c|c|c|}
\hline Time & Day I & Day 2 & Day 3 & Day 4 \\
\hline $9: 00-10: 30$ & $\begin{array}{l}\text { Introduction and Course Overview } \\
\text { Dr Vasantha Muthuswamy - ICMR } \\
\text { Dr Peter A. Singer - University of Toronto } \\
\text { Dr Abdallah S. Daar - University of } \\
\text { Toronto }\end{array}$ & $\begin{array}{l}\text { Ethical guidelines for Medical } \\
\text { Research in India } \\
\text { Dr N.K. Ganguly - ICMR }\end{array}$ & $\begin{array}{l}\text { Intellectual Property Rights } \\
\text { DrMalathi Lakshmikumaran - } \\
\text { TERI }\end{array}$ & $\begin{array}{l}\text { Opinion Leaders' Network } \\
\text { Dr Peter A. Singer } \\
\text { Dr Rakesh Dubey - Ocimum } \\
\text { Biosolutions }\end{array}$ \\
\hline $11: 00-12: 30$ & $\begin{array}{l}\text { New Science I : Genomics } \\
\text { Dr S. S. Agarwal - ACTREC } \\
\text { DNA Vaccines - Relevance for India } \\
\text { Dr G. Padmanabhan - IISC }\end{array}$ & $\begin{array}{l}\text { Business Models } \\
\text { Dr Chandu Nair - Scope } \\
\text { Marketing \& Knowledge } \\
\text { National Systems of Innovation } \\
\text { Dr Peter A. Singer }\end{array}$ & $\begin{array}{l}\text { Public Health - Community } \\
\text { Ownership } \\
\text { Dr Saraswathi Sankaran - } \\
\text { DESH }\end{array}$ & \\
\hline $2: 00-3: 30$ & $\begin{array}{l}\text { New Science } 2 \text { : Stem Cells } \\
\text { Dr Dipika Mohanty - ICMR (Institute of } \\
\text { Immunohaematology) }\end{array}$ & $\begin{array}{l}\text { Indian Business Perspectives } \\
\text { Mr Khalil Ahmed - Shanta } \\
\text { Biotech } \\
\text { Dr Krishna Ella - Bharath } \\
\text { Biotech }\end{array}$ & $\begin{array}{l}\text { Group Presentations } \\
\text { Biotechnology: From Benches } \\
\text { to Bedside } \\
\text { Dr Rajesh Behl - Centre for } \\
\text { Human Genetics }\end{array}$ & Group Presentations \\
\hline $4: 00-5: 30$ & $\begin{array}{l}\text { Genomics and Global Health } \\
\text { Dr Abdallah S. Daar }\end{array}$ & $\begin{array}{l}\text { Pharmaco-genomics } \\
\text { Dr C. M. Gupta - CDRI } \\
\text { Dr Vasantha Muthuswamy } \\
\text { Dr R. H. Jani - German } \\
\text { Remedies }\end{array}$ & $\begin{array}{l}\text { Legal Regulations of Genomics } \\
\text { - Emerging Scenario } \\
\text { Dr Madhava Menon - WB } \\
\text { National } \\
\text { University of Juridical Sciences }\end{array}$ & $\begin{array}{l}\text { Summing up } \\
\text { Dr Sandhya Tewari - CII } \\
\text { Discussion \& Closing - Dr } \\
\text { Peter A. Singer }\end{array}$ \\
\hline
\end{tabular}

Both course participants as well as presenters for each session were identified through a combination of recommendations from field experts in India and searches on ICMR's database of experts. These efforts were augmented by assistance from the Confederation of Indian Industry. People identified to participate in the course included scientists from academic centres and industry, industry executives, regulatory officials, representatives from the legal sector, NGOs and media. The participants were carefully chosen in an attempt to represent a wide range of interests in the emerging area of genomics in India. In total there were 52 participants, and the represented institutions are listed in Figure 2.

The sessions dealt with a wide range of relevant topics, starting with recent scientific advances in genomics and stem cell research, followed by discussions on business models in genomics and biotechnology, intellectual property rights and regulatory frameworks, public engagement and an internet-based opinion leaders' network. A detailed time-table of the program is shown in Table 1. The presentations were designed to be interactive and foster active discussion from the participants. Most presenters used Microsoft powerpoint presentations, or overhead transparencies, and, where appropriate, additional visual aids such as video films. Each session set aside at least 45 minutes for discussion and participation. Participants were encouraged to read supporting materials (Figure 3) prepared prior to the meeting (in consultation with presenters) in order to enhance their in-class experience and maximize the benefits from the presentations and the class discussion. Materials included peer-reviewed articles, as well as news items, patents, and material from other sources. The facilitators (in particular PAS) summarized the main points at the end of each lecture, facilitated the discussion and maintained continuity and focus throughout the course. Early in the course, the attendees were placed into one of five study groups - these groups were carefully chosen to capitalize on the diversity in background and expertise of the participants. The overall task of these study groups was to draw upon the course material and their own experiences and propose a set of recommendations for genomics and biotechnology policy in India. The groups met frequently to discuss the presentations, and each participant was also provided a course reader with additional background reading materials on the lecture topics. In order to assess the level of interest in the formation of an email-based opinion leaders' network, a brief survey was conducted on the participants' internet access and their expectations of the network.

\section{Results}

The first day of the course introduced participants to one another, and to the overall purpose and objectives of the course (Figure 1). The day's presentations began following the welcome address by conveners from ICMR and University of Toronto, and a brief overview of the status of genomic research in India. The three presentations of the day were dedicated to familiarizing the participants with the latest scientific advances in genomics and biotechnology, and their relationship to international health, particularly to health in developing countries. Dr S.S. Aggarwal, Director ACTREC, presented background information on genomics and discussed the revolution in life sciences that 
A.D. Nageswari - Directorate of Medical Education, Chennai Abdallah Daar - Joint Centre for Bioethics, University of Toronto

Alok Kumar - Proagro Seed Co. Pvt Ltd (Bayer CropScience)

Asis Datta - International Centre for Genetic Engineering \& Biology, JNU

C.M. Gupta - Central Drug Research Institute

Chandu Nair - Scope marketing \& Information Solutions Pvt Ltd

D.Varatharajan - Sree Chitra Tirunal Institute for Medical Sciences and Technology

Dinesh C. Sharma - The Lancet Oncology

Dipika Mohanty - Institute of Immunohaematology, ICMR

G. Padmanabhan - Indian Institute of Sciences (IISc)

G.S. Khatre - Bharat Biotech International Ltd

Geeta Jotwani - ICMR

Jai Rup Singh - Guru Nanak Dev University

K.Ramamoorthy - Kerala Government

Kasturi Dutta - Special Centre for Molecular Medicine, JNU

Khalil Ahmed - Shantha Biotechnics Pvt Ltd

Krishna Ella - Bharat Biotech International Ltd

M. Jayaprasad - Malayala Manorama

Malathi Lakshmikumaran - Tata Energy Research Institute

Manoranjan Hota - Ministry of Environment \& Forests

Moinak Banerjee - Rajiv Gandhi Centre for Biotechnology

N.K. Ganguly - ICMR

N.K. Mehra - All India Institute of Medical Sciences

N.R. Madhava Menon - West Bengal National University of Juridical Sciences

Nandini K. Kumar - ICMR

P.R. Sudhakaran - Kerala University

P.S. Maruthi Sai - Dr Reddy's Laboratories Ltd.

Peter Singer - Joint Centre for Bioethics, University of Toronto

Poonam Salotra - Institute of Pathology, ICMR

Prochi Madon - Reliance Life Sciences Pvt. Ltd.

R. S. Paranjape - National AIDS Research Institute, ICMR

R.H. Jani - German Remedies

Rajeev Soni - Ranbaxy Lab. Ltd

Rajesh Behl - Centre for Human Genetics

Rakesh Dubey - Ocimum Biosolutions Ltd

S. C. Sehgal - Regional Medical Research Centres, ICMR

S.S. Agarwal - Advanced Centre for Treatment, Research and Education in Cancer Sandhya Srinivasan - freelance journalist

Sandhya Tewari - Confederation of Indian Industry

Sandip Basu - National Institute of Immunology

Sachin Chaturvedi - Research \& Information Systems

Sarala K. Subba Rao - Malaria Research Centre, ICMR

Saraswathi Sankaran - Deepam Educational Society for Health (DESH)

Subbiah Arunachalam - M.S. Swaminathan Research Foundation

Sujatha Narayanan - Tuberculosis Research Centre, ICMR

Suman Sahai - Gene Campaign

T.S. Rao - Department of Biotechnology, Ministry of Science \& Technology

Tara Acharya - Joint Centre for Bioethics, University of Toronto

V. Mohanan Nair - Sree Chitra Tirunal Institute for Medical Sciences and Technology

V. Vasanthi - Directorate of Public Health and Preventive Medicine, Govt of Tamil Nadu

Vasantha Muthuswamy - ICMR

Vinod Varshney - Hindustan Times

\section{Figure 2}


Cahill, Lisa Sowle (2001) "Genetics, Commodification, and Social Justice in the Globalization Era", Kennedy Institute of Ethics Journal, 11(3), p. 221-238

Caulfied, Timothy, E. Richard Gold and Mildred K. Cho, "Patenting Human Genetic Material: Refocusing the Debate", Science and Society, [pages? year?]

Chaturvedi S (2002) Status and Development of Biotechnology in India: an Analytical Overview. http://www.ris.org.in/dp28_pap.pdf.

CIHR (January 2002) "Human Pluripotent Stem Cell Research: Recommendation for ClHRFunded Research", Report of the Ad Hoc Working Group on Stem Cell Research, www.cihr.ca/cgi-bin/cihr_print.pl

Collins, Beverly A. et al. (July 2000) "From Theory to Practice: Identifying Authentic Opinion Leaders to Improve Care", Managed Care, p. 56-62

Daar AS, Thorsteinsdottir H, Martin DK, Smith AC, Nast S, Singer PA. (2002) Top ten biotechnologies for improving health in developing countries. Nat Genet.;32(2):229-32.

Enriquez, Juan and Ray A. Goldberg (March-Arpil 2000) "Transforming Life, Transforming Business: The Life-Science Revolution", Harvard Business Review, p. 96-104

Gaskell, George et al. (September 2000) "Biotechnology and the European Public", Nature Biotechnology, Vol 18, p. 935-938

ICMR (2000) Ethical Guidelines for Biomedical Research on Human Subjects. Indian Council of Medical Research. New Delhi 2000. http://icmr.nic.in/ethical.pdf

Lemmens, Trudo (1999) "Private Parties, Public Duties: The Shifting Role of Insurance Companies in the Genetics Era", Genetic Information: Acquisition, Access and Control, Alison Thompson and Ruth Chadwick, Eds, Kluwer Academic/Plenum Publis, p. 31-39

Lemmens, Trudo (March 1997) "What About Your Genes?" Ethical, Legal, and Policy Dimensions of Genetics in the Workplace", Politics and the Life Sciences, 16(1), p. 57-75

Melzer, David (1998) "Patent Protection for Medical Technologies: Why some and not others?", Lancet, Vol 351, p. 518-19

Owens, Kelly and Mary-Claire King (October 1999) "Genomic Views of Human History", Science, Vol 286, p. $451-453$

Pang T \& Weatherall D (2002) Genomics and Global Health. BMJ Vol 324, $4^{\text {th }}$ May p.1051-52

Roses, Allen D. (June 2000) "Pharmacogenetics and the Practice of Medicine", Nature, Vol 405 , p. $857-865$

Scherer, Stephen (Autumn 2001) "The Human Genome Project", ISUMA, p. 11 - 19

Singer PA, Daar AS. (2001) Harnessing genomics and biotechnology to improve global health equity. Science;294(5540):87-9.

Wolf, Susan M. (1995) "Beyond "Genetic Discrimination": Toward the Broader Harm of Geneticism", Journal of Law, Medicine and Ethics, 23, p. 345-53

\section{Figure 3}


genomics has brought about. Dr G. Padmanabhan, Emeritus Scientist, Indian Institute of Science spoke on the relevance of DNA vaccines have been heralded as third vaccine revolution and how developing countries like India should develop it as a cost-effective alternative with indigenous expertise and international help. Dr Dipika Mohanty of the Institute of Immuno-haematology at KEM hospital brought the participants up to speed on the latest research in stem cells. Dr Abdallah Daar of the University of Toronto Joint Centre for Bioethics closed the day with a discussion of the impact of genomics and related biotechnologies on global health, emphasizing the ten biotechnologies that are the best candidates to address the health needs of developing countries [3]. A rich discussion followed each session, with participants focusing on both the latest scientific developments, as well as their potential impact for health in the developing world, in particular India. Some participants were enthusiastic about these developments, while others remained sceptical about the immediate benefits for the developing world.

On the second day, Dr N.K. Ganguly, Director-General of ICMR, presented an overview of the progress of biotechnology in India and the need for a revision of ethical guidelines in medical research, emphasizing the need to link science and society, allocation of resources for health, and the disconnect between industrial policy and health policy in India. This lecture was followed by a focus on industry perspectives, with an introduction on worldwide business models in the biotechnology sector by $\mathrm{Mr}$ Chandu Nair, Director, Scope e-knowledge Centre. Dr Peter Singer of the University of Toronto then discussed the concept of national systems of innovation, with examples from the industrialized world (Canada and the United States) as well as emerging economies like India and Cuba. Mr Khalil Ahmed, Executive Director at Shantha Biotech and Dr Krishna M. Ella director Bharat Biotech provided the participants with their own concrete examples from the perspective of the Indian biotechnology industry, bringing into the spotlight the importance of private enterprise in the quest for global health equity. The day ended with a discussion of pharmacogenomics and its potential for improving health in India, presented by Drs R. H. Jani, MD German Remedies, and C. M. Gupta, Director, CDRI and the ethical issues pertaining to this new area presented by Dr Vasantha Muthuswamy. This day saw animated discussions on collaborations between the public and private sectors to foster biotechnology in India, as well as the role of government policy in encouraging investment in the private sector and academia. There was also a discussion of ethics, confidentiality and privacy issues and intellectual property rights triggered by the session on pharmacogenomics.
The third day opened with an interactive session on intellectual property rights, led by Dr Malathi Lakshmikumaran of TERI, which generated a good deal of debate on traditional knowledge and its ownership. Dr Saraswati Sankaran then brought to light the importance of public engagement to realize the potential of biotechnology in health improvement, using the example of her Organisation DESH's HIV/AIDS initiative. This talk was followed by group work and a discussion by the participants, on public engagement interventions for biotechnology based on the role of the settings assigned to each group (Media; Educational institutions; Hospitals; Workplace; Slumdwellers). Some of the practical suggestions from the participants included school field trips to biotechnology laboratories and training in the workplace on ethical concerns regarding genetic profiling. Dr Madhava Menon then presented a discourse on the emerging scenario regarding the legal regulation of genomics and its important inclusion in juridical sciences. Dr Rajesh Behl from the Center for Human Genetics, Bangalore, followed with a lecture on how best to translate the benefits of basic scientific research to practical medical interventions. This intensive day ended with the participants working in groups to use the material that had been presented in the course in order to address the underlying question: how to harness the benefits of genomics and biotechnology to improve health in India.

The final day of the course set out with Drs Rakesh Dubey of Ocimum Biosolutions and Peter Singer presenting their thoughts on the proposed internet-based Opinion Leaders' Network - the main goal of which is to encourage further interaction between the participants (as well as other interested individuals) with an overarching aim to create sound genomics policy in India. Both noted that it would be essential to have wide representation, active participation from all sectors and open discussion. A survey was conducted to assess the participants' level of interest in establishing such a network, and what they expect to achieve from it. Following this, the participants were given three hours to work on their presentations, and the course re-convened after lunch.

The five groups were each given the opportunity to present their views of the most important aspects of the course, and how best to use genomics and biotechnology to address India's health needs. While it was generally agreed that the biotechnology sector (encompassing both public and private efforts) has grown over the last ten years and that genomics has the potential to alleviate India's health problems, the course participants also emphasized the importance of effective regulatory systems, intellectual property rights and ethical and social issues related to genomics and public health. In his role as facilitator, Peter Singer then identified recurring themes in 


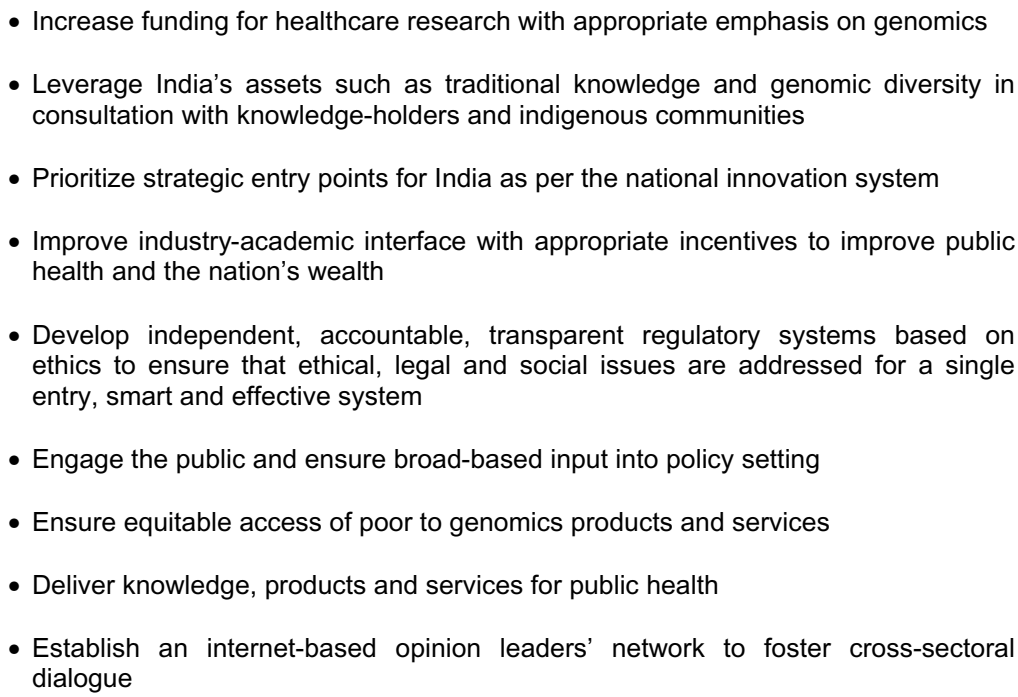

\section{Figure 4}

Recommendations Emerging from the Course Discussion

these presentations and synthesized them into seven overall recommendations for genomics policy in India. An intensive debate followed, as participants deliberated over these recommendations with regard to their suitability to the Indian economy, health needs and the biotechnology sector. The recommendations were modified accordingly by the participants. The final recommendations emerged over the course of the debate (Figure 4), and these will be discussed further below.

\section{Discussion \\ Increase funding for healthcare research with appropriate emphasis on genomics}

Currently, the total funding for health research in Central governmental institutions in India is a little over US \$100 million - these funds are allocated to the control of communicable and non-communicable diseases, patient care, medical education, training, and research with the latter three accounting for about $60 \%$ of the funds [4]. In contrast, the budget for the US National Institutes of Health for basic biosciences R\&D alone was $\$ 23.6$ billion in 2002 , or about $1 \%$ of the total US government budget [5]. Therefore, even though India's purchasing power parity inflates this level of funding, it still represents less than
$0.5 \%$ of the total budget (approximately $\$ 92$ billion for the year 2003-4).

Not surprisingly, therefore, there was consensus among the course participants that the Indian government needs to increase funding for health research, with appropriate emphasis on genomics and related biotechnology. The Department of Biotechnology (under the Ministry of Science and Technology) and the Indian Council of Agricultural Research (ICAR) have also stressed the importance of increased government funding for biotechnology research and development in general and are requesting US \$560 million for R\&D from the federal government for the tenth five-year plan. These funds will be used for ongoing and new programs in vaccine research, genomics, transgenic plants and animals, and technology transfer. The DBT also expects to support state governments in building biotechnology parks and research centres [6].

The private sector, for its part, has also faced financial hurdles. Biotechnology companies have found it difficult to attract both government as well as venture capitalist funding (Indian survey). This is partly due to the perception of biotechnology market as uncertain, especially over the last 
two years, but there was considerable debate during the course over the fact that funding for R\&D in the biological sciences has been directed mostly at the public sector, with few incentives for the private sector. Key government-funded research centres in India include the Indian Council for Medical Research; the National Centre for Biological Sciences in Bangalore (owned by the Tata group); the Tata Institute for Fundamental Research; the Centre for Cellular and Molecular Biology. ICMR is expected to receive US $\$ 30$ million over five years from the Ministry of Health for genomics, stem cell and structural biology research. The funding will be divided among various research centres and medical institutions under the direction of ICMR, and will focus, among other diseases, on leprosy, TB, rheumatic fever and $\beta$-thalassemia [7].

\section{Leverage India's assets such as traditional knowledge and genomic diversity in consultation with knowledge-holders and indigenous communities}

India has $7 \%$ of the world's biodiversity and with it a treasure of traditional knowledge of the medicinal properties of indigenous plants [8]. Moreover, the genetic diversity of the population makes the country a tremendous source of information for research in genetic epidemiology. The Indian Genome Initiative (IGI) is a project launched by the DBT to study the genetic variation of the Indian population. The program has funding support of US $\$ 20$ million over five years. A network of four gene banks has also been set up for the conservation of rare, endangered and commercially important medicinal and aromatic plants, and a program has been initiated for the development of herbal products with the help of biotechnology tools [6]. Dr Malathi Lakshmikumaran's presentation of India's successes in overturning the Basmati rice and turmeric patents highlighted the issue of intellectual property rights over traditional knowledge in developing countries. The former patent was seen as a serious economic threat for rice exporters from India and Pakistan. In 1997, the Texas-based firm RiceTec was granted a patent on 'basmati rice lines and grains' by the USPTO on the basis of 20 claims. India and Pakistan challenged three of the claims that related to the grain quality (such as elongation in cooking and the characteristic aroma of basmati grains). Following re-examination of the patent, Rice Tec has withdrawn these claims and can no longer use the name "Basmati" for its rice lines. The turmeric patent was seen as a rather opportunistic attempt to own exclusive rights to a natural product that has been used in India for medicinal purposes for centuries. In 1995, two U.S. based Indians were granted a patent for the use of turmeric in wound healing. The invention claimed under the patent was the use of turmeric at the site of an injury and/or its oral intake to promote the healing of a wound. An extensive search yielded indigenous medical texts, some over
100 years old, that challenged the novelty of the use of turmeric in healing wounds, leading the USPTO to revoke the patent.

The value of these traditional assets is widely recognized, and the participants acknowledged that they need adequate protection and benefit sharing so that indigenous communities are not exploited and are the recipients of the products of research conducted on them. According to the DBT, sixteen genetic diagnosis and counselling units have been set up in the country for prenatal diagnosis and counselling for major genetic disorders. Almost fourteen thousand affected families have benefited from this programme. A few thousand people belonging to socially underprivileged groups have been screened for detecting various genetic disorders. A National Bioethics Committee has formulated policies for the ethics of research in human genetics and genomics, and ICMR guidelines on human genetics have been legislated. The DBT has also developed policies on ethics and regulatory issues in biotechnology [9].

\section{Prioritize strategic entry points for India as per the national innovation system}

As India makes forays into genomics and bioinformatics, it will be important to prioritize the country's health needs and strategic entry points. An estimated 4 million people are living with AIDS in India [10], over 2 million people are infected with malaria per year [11] and over 420,000 Indians die annually from tuberculosis [12]. On the other hand, chronic diseases like cancer, diabetes and heart disease are also prevalent in India and pose a rising health concern. Both these broad categories of disease present $R \& D$ opportunities for India. Moreover, India's biotechnology and pharmaceutical industries are also in a good position to prioritize and develop indigenous technologies. For example, the announcement by the US Department of Health in 2002 of 64 stem-cell lines that will be funded by the US federal government creates opportunities for stem cell research in India - Reliance Life Sciences has 7 of these cell lines. The Indian biotechnology industry is ranked third in the world in terms of stem cell research, primarily because both the government and private industry have invested heavily in research institutes studying stem cells. The World Health Organization, in its 2002 report on Genomics and World Health, also urges Member states to build genomics and bioinformatics capacity for research towards their own health priorities in order to address global health inequities [13]. India can, and has already begun to, translate its successes in software technology into bioinformatics capability.

In January 2002, the DBT also articulated priority research areas for government funding in biotechnology. These areas include vaccines based on genomic research for 
cholera, malaria, AIDS, rabies and tuberculosis as well as biofertilizers, biopesticides, transgenic crops, and gene therapy for cancer treatment. A biotechnology vision document released in late 2001 outlines additional plans over the next 10 years and includes developing edible vaccines for specific disease targets, testing and approving a series of GM crops, developing additional vaccines and diagnostic tools for major communicable diseases, as well identifying and protecting biodiversity "hot spots."

There is considerable concern among NGOs and other stakeholders in India that the DBT's goals are too broad and difficult to realize. Moreover, it is doubtful that these activities will help to meet the health needs of the economically weaker sections of society. It is widely felt, and this sentiment was echoed during the course, that India needs a clearly articulated genomics and biotechnology policy that will focus biotechnology research on domestic needs.

In February 2001, ICMR launched a genome initiative and approved 101 out of 167 proposals for research at centres for molecular medicine and bioinformatics units in areas including vaccines, microbial genomics, vector genomics, molecular genetics of haematological disorders, population genetics, pharmacogenetics, nutrition genomics, and neurogenetics.

Private sector efforts in biotechnology have so far focused mainly on the development of vaccines and therapeutic recombinant proteins for infectious diseases. A number of biotechnology products are in various stages of development. Hyderabad-based Shantha Biotech's recombinant hepatitis-B vaccine was launched in 1997, and in 2002 Shantha also launched alpha-interferon "Shanferon" in parts of the country. Shantha Biotechnics has recently become the first Indian company to obtain World Health Organization certification of the hepatitis- $\mathrm{B}$ vaccine, opening the way for entities like UNICEF to purchase this low-priced product for their programs. Last year, UNICEF ordered 8.5 million doses of Shanvac B, worth $\$ 5$ million, for worldwide distribution. Another promising Indian biotechnology company is Hyderabad-based Bharat Biotech International, which launched its brand of hepatitis$B$ vaccine, Revac- $B$, in January last year. Bharat Biotech boasts a production capacity of 100 million doses, possibly the largest in the Asia-Pacific region [14].

\section{Improve industry-academic interface with appropriate incentives to improve public health and the nation's wealth}

A recurring theme throughout the course discussions was the public-private interface in health research, and how to create greater fluidity between the two while simultaneously ensuring incentives for industry growth and improv- ing public health. The United States appears to present one successful model of a fluid industry-academic interface, wherein an academic discovery can be leveraged to launch a commercial product - the earliest such example in biotechnology being Genentech which pioneered the industry through the commercial application of recombinant DNA techniques [15].

The biotechnology industry is capital intensive, and the funds required for biomedical research can often be mobilized only with the help of the private sector. Forging public-private partnerships will allow the public sector to have access to some of these funds, and allow private companies access to public resources.

There was considerable debate among the participants on striking a balance between improving public health in India while at the same time ensuring that commercial incentives remain strong and India's economic growth, particularly in the area of scientific research and biotechnology, is not hampered.

The Government of India has introduced some incentives for the biotechnology industry, for example it now emphasizes upgrading scientific research and allows duty free import of selected equipment for biotechnology research. In his inaugural address at the $90^{\text {th }}$ session of the Indian Science Congress, the Indian prime minister A.B. Vajpayee also appealed to the private sector to "invest more in indigenous $R \& D$, in partnership with our $S \& T$ institutions, IITs (Indian Institutes of Technology) and universities, so that their products and services become globally competitive" [16]. Vajpayee also mentioned the disturbing phenomenon of "brain-drain" - both the migration of talented Indian scientists and technologists to developed countries, as well as the diversion of talent away from $R \& D$ careers to non-scientific careers in both Government and the private sector. He stressed the need to take concrete steps to give promising scientists and technologists the necessary opportunities, recognition, and adequate material compensation.

The DBT maintains that it has promoted and accelerated the pace of development of biotechnology in India - but a criticism of its policies is that these incentives have been aimed largely at government-supported research centres. Meanwhile, according to a market assessment report by Canada's Department of Foreign Affairs and International Trade, there are as many as 175 biotechnology companies active in the Indian market; up to 50 of those companies work on advanced biotechnology applications [17]. Approximately $60 \%$ of the industry is devoted to human health applications, $10 \%$ to agricultural biotechnology and $30 \%$ to industrial applications, bioinformatics and genomics. Increased collaboration between companies 
and the public sector may accelerate growth of the industry while at the same time focusing development in the areas of greatest need.

In 2001, the Malaria Vaccine Initiative at PATH (Program for Appropriate Technology in Health, a US-based nonprofit organization), the New Delhi site of the International Centre for Genetic Engineering and Biotechnology (ICGEB), and the biotechnology firm, Bharat Biotech International Limited in Hyderabad, India, announced an agreement to jointly develop a vaccine with the potential to prevent malaria caused by the parasite Plasmodium vivax, transmitted through mosquito bites [18]. Nearly 65 percent of all malaria cases in India are caused by $P$. vivax. This type of public-private partnership is encouraging for public health in developing countries.

\section{Develop independent, accountable, transparent regulatory systems to ensure that ethical, legal and social issues are addressed for a single entry, smart and effective system}

Genomics is a rapidly evolving science that has the potential to be beneficial to public health but could also be misused and carries with it a number of ethical, legal and social implications. For example human genetic profiling data could be used to discriminate against individuals in terms of their employment or eligibility for health insurance. This and other eventualities require the establishment of an effective, transparent and accountable regulatory system. The field of genomics has an impact on basic human rights - to life, equality, information, choice and privacy. It also raises other legal issues such as trade and intellectual property rights. It is, therefore, the function of an effective regulatory system to balance commercial interests with human rights.

The regulatory system in India for biotechnology products has been criticized by the All India Biotechnology Association (established in 1994 as a non-profit society to represent the interests of all those engaged in various aspects of biotechnology) for being bureaucratic and secretive[19]. AIBA has called for a fundamental re-structuring of the regulatory system and for additional private sector resources as a way to stimulate growth in the industry. It has also proposed a national regulatory agency for all biotechnology products under direct authority from the prime minister and independent of various government departments and ministries in order to reduce time for regulatory approval. This is one possible solution, but some course participants disagreed with the notion of a single regulatory body, pointing out that the different pace of development of the biotechnology sector in various states in India may require state-specific regulatory systems.
Dr Madhava Menon's suggestion at the Genomics Policy course of the Telecommunications Regulatory Authority of India (TRAI) serving as a potential model for biotechnology regulatory reform was met with some enthusiasm. The aim of this endeavor is to transfer the regulatory powers of the government to TRAI for most purposes, such as determining tariffs, monitoring revenue-sharing between operators (including the Government's Department of Telecommunications), settling disputes between operators and protecting consumer rights. While this may not be the ideal model for biotechnology, it does, along with AIBA's recommendations, provide the impetus and rationale for an autonomous regulatory body within a market economy.

\section{Engage the public and ensure broad-based input into policy setting}

Good public policy is based on informed public opinion and the process of public engagement is closely linked with consensus-building and policy formulation. The goal of public engagement is to elicit a broad range of opinions on contentious issues in genomics, such as genetic testing, GM foods and intellectual property rights. Issues related to genomics and biotechnology should therefore be publicized to and discussed by a broad audience of stakeholders, including scientists, regulatory officials, lawyers, journalists, the private sector and consumers. For instance, it will be vital to engage and educate the public on developments in genomics in order to encourage acceptance of novel biotechnology products as they reach the market. Dr Saraswathi Sankaran brought to light the importance of public engagement to realize the potential of biotechnology in health improvement, using lessons learned from the experience of the non-governmental organization Deepam Educational Society for Health (DESH) in health awareness promotion. DESH's programs are conducted in three phases: information and awareness; empowerment with accountability; and collective, community action. Following this presentation, the participants discussed the importance of genomics and public engagement in various settings, such as hospitals, educational institutions, the workplace, media and slumdwellers. This helped to highlight informational requirements specific to each setting, making it clear that broadly representative input within policy decision-making bodies would help to formulate genomics policy that is wellgrounded in societal needs. The participants made a number of valuable suggestions, one of them being the possibility of setting up multilingual websites for public education as well as consultation. 


\section{Deliver knowledge, products and services for public health and ensure equitable access of the poor to genomics products and services}

India is uniquely positioned as a developing country with strong biotechnology capabilities to set an example in ensuring equitable access of its poor to biotechnology products. Indian scientific and medical expertise can contribute to the effort to address these health needs using the latest advances in genomics and biotechnology, and the Indian market represents opportunities to supply vaccines and therapeutics to poor consumers - but at what cost? There was no question among the course attendees that ensuring access of the poor to these products is a daunting task. This is where the government may have to take the lead role in striking a balance, providing appropriate incentives for the biotechnology industry while at the same time ensuring equitable access to biotechnology products. Again, India's biotechnology policy will be crucial to the achievement of equitable access.

Shantha Biotech, which was first to launch the indigenously developed hepatitis-B vaccine in the country in 1997, has secured the WHO certification for its product "Shanvac B" (now marketed at "Hepashield"). Shantha is the only company in India to get this certification for the hepatitis-B vaccine, and it is being provided at a quarter the price of the previously imported vaccine [20]. Although this price still puts it out of reach of the poorest Indians, more people have access to Shantha's product than to the imported vaccine. This suggests that building the private sector in India may help to improve access to biotechnology products that would otherwise have to be imported.

\section{Opinion leaders' network}

There was unanimous endorsement on the part of the course attendees of the formation of an opinion leaders' network that will serve as a forum to discuss the issues mentioned above and arrive at some policy decisions, and perhaps allow for policy papers that can be presented to the Government of India for further action. The internetbased network will be moderated in order to streamline discussions. A number of short-term projects are envisioned that could be coordinated by various expert members of the network. The results of a survey administered to the participants during the course suggested that $90 \%$ of them had reliable access to internet and would be willing to spend 1-2 hours a week taking part in the discussion. The main objectives of the network, as identified by the participants in the survey, would be dissemination of information, exchange of ideas, maintaining inter-connectivity, consensus building through wide participation, and influencing policy and media. Other key results from the survey are summarized in table 2 below.

\section{Conclusion}

Health advances in developing countries have lagged behind those in the developed world. The rapid advance in genomics research in developed countries compared with the relatively slow progress of genomics $R \& D$ in developing countries threatens to create a North-South genomics divide in the coming years, which may enhance existing health inequities. India has the unique opportunity, as a developing country with highly skilled scientists and medical professionals, to play a leadership role in closing the genomics divide. With the appropriate emphasis on its health needs, incentives for public-private R\&D partnerships, and a sound set of regulatory policies, India may well set an example for the rest of the world. The overall goal of the Genome Policy Executive Course, an Indo-Canadian initiative, was to help provide the impetus for cross-sectoral dialogue on genomics and health policy in India.

Table 2: Opinion Leaders' Network Survey Results

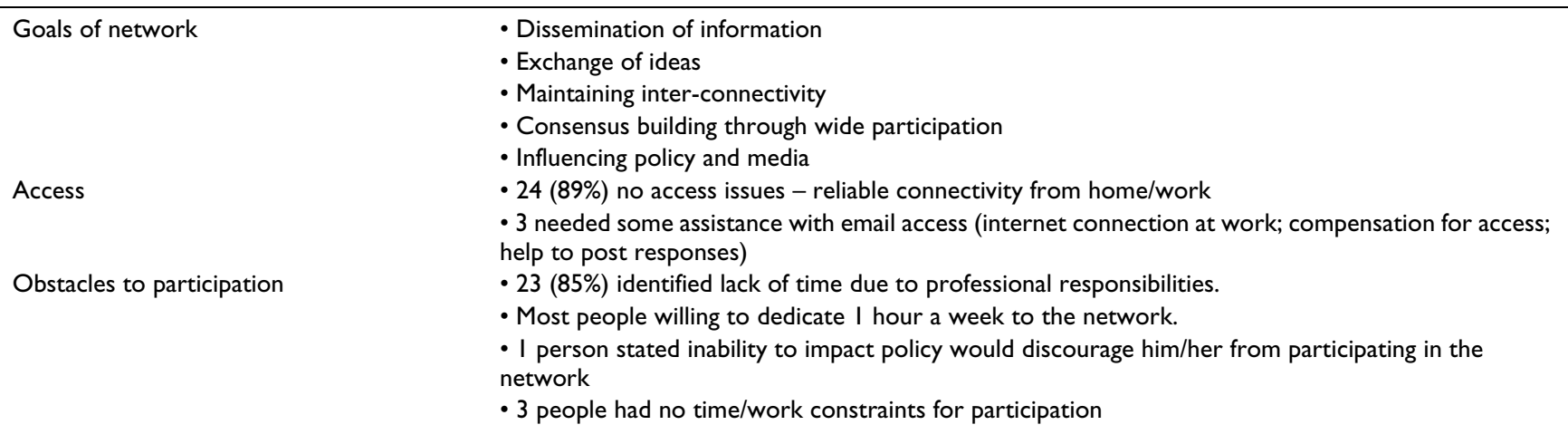


Research and development in genomics in developing world will follow its path with or without courses of this nature. The main limitation of a course of this nature is the difficulty in maintaining focus with interdisciplinary discussion and achieving consensus in a large group with varying perspectives. However, it is a window into, and a seed for well-informed inter-sectoral policy formulation. Where this course is useful is in fostering a multidisciplinary discussion that can contribute to policy formulation by bringing together individuals from different sectors and exposing them to alternative perspectives. The key advantage of this course is that it can help bring policy to the forefront so that ethical, social, and legal aspects of new technologies do not lag behind as science forges ahead. Without sound policy that keeps up with new science, its benefits will be difficult to realize, and its risks contained.

Although there are clearly some unique aspects to our experience in India, it appears that the conceptual framework of the course can be applied to other regions too. Two other courses have been held, one in Africa and the other in the Middle East. The Africa course, held in Nairobi, Kenya in March 2002, was attended by representatives from 10 different nations. Its main themes for discussion included the need for capacity-strengthening, financial investment for $\mathrm{R} \& \mathrm{D}$ and commercialization, the role of cross-sectoral partnerships, the need to engage government and also to educate the public. A similar internetbased network, the African Genome Policy Forum, has also been established. More recently, a similar course was jointly organized with the World Health Organization's Eastern Mediterranean Regional Office and held in Muscat, Oman to serve the countries of the region (it was attended by representatives from 13 countries). A concrete recommendation emerging from the course is the creation of National Biotechnology Councils in each country, which will undertake, among other things, formulation of national biotechnology policy. Two other courses, in Latin America and in China, are being planned and will be held in 2004.

While the experience in India may not be exactly the same as in other regions of the world, there is some evidence that a similar framework, with appropriate modifications to session topics and participant representation could be held elsewhere too. For instance, our procedure has now led to three courses in three regions, with the formation of regional networks in each place - Africa, India, and the Eastern Mediterranean Region (where the course was organized jointly with the World Health Organization's Eastern Mediterranean Regional Office). Similar courses are now being planned for Latin America and China. The regional genome policy networks can provide models to establish a Global Genome Policy Forum.

\section{Competing interests}

None declared.

\section{Authors' contributions}

All authors participated in and contributed to the course. TA drafted the manuscript. The course was convened and coordinated by NK and VM. PAS and ASD conceived of the course, and participated in its design and coordination.

\section{Acknowledgements}

We would like to thank the course participants and members of the Indian Genome Policy Forum for their insightful comments and suggestions. The Canadian Program in Genomics and Global Health receives most of its funding from the Ontario Research and Development Challenge Fund, and Genome Canada through the Ontario Genomics Institute. Matching partners for some of the projects include the Fogarty International Center, Food Biotechnology Communications Network, Food Systems Biotechnology Centre, GlaxoSmithKline, The Hospital for Sick Children, Indian Council for Medical Research, International Development Research Centre (IDRC), the McLaughlin Centre for Molecular Medicine, Merck and Co, Mount Sinai Hospital, Sunnybrook and Women's College Health Sciences Centre, University of Guelph, University Health Network, University of Toronto, and the World Health Organization. Peter A. Singer is supported by a Distinguished Investigator award from the Canadian Institutes of Health Research.

\section{References}

I. World Health Report: Making a Difference. World Health Organization, Geneva 1999.

2. America's pain, India's gain; at least one corner of the IT world is booming. Economist 2003:57.

3. Daar AS, Thorsteinsdottir H, Martin DK, Smith AC, Nast S, Singer PA: Top 10 biotechnologies for improving health in developing countries. Nat Genet 2002, 32:229-232.

4. Ministry of Health and Family Welfare, India Annual Report (1999-2000).

5. National Institutes of Health [http://www.nih.gov]. Accessed March 2003

6. Biotechnology - A Vision (Ten Year Perspective) Department of Biotechnology, Ministry of Science and Technology, India 2001 [http:// dbtindia.nic.in/aboutdbt/overviewmain.html]. Accessed February 2003

7. Chaturvedi S: Status and Development of Biotechnology in India: an Analytical Overview. 2002 [http://www.ris.org.in/ dp28 pap.pdf]. Accessed February 2003

8. National Policy and Macrolevel Action Strategy on Biodiversity. Ministry of Environment and Forests, Government of India 1999.

9. Biotechnology - In Pursuit of Excellence and Relevance for Human Kind 2001 [http://dbtindia.nic.in/aboutdbt/overview
[ main.html]. Accessed February 2003

10. UNAIDS [http://www.unaids.org]. Accessed March 2003

II. Malaria Site [http://www.malariasite.com/index.htm]. Accessed January 2003

12. USAID [http://www.usaid.gov]. Accessed January 2003

13. Genomics and World Health - Report of the Advisory Committee on Health Research. World Health Organization, Geneva 2002.

14. Business World India. Competition snapping at Shantha Biotech's heels 2000 [http://www.businessworldindia.com/archive/ 201023/cover $2 . \mathrm{htm}]$.

15. Genentech [http://www.genentech.com]. Accessed March 2003

16. Inaugural address by Prime Minister Atal Bihari Vajpayee at the 90th Session of the Indian Science Congress [http:// www.24framesdigital.com/isro/isro.htm]. Accessed January 2003 
17. MSDT Market Research Centre: Biotechnology Market in India 2002 [http://atn-riae.agr.ca/asia/e3335.htm]. Accessed February 2003

18. Malaria Vaccine Initiative [http://www.malariavaccine.org/files/ 0107II-MVI-India-pr.htm]. Accessed March 2003

19. Jayaraman KS: Indian regulatory system stifles industry growth. Nat Biotech 200I, 19:105-106.

20. Technology Information, Forecasting \& Assessment Council [http://www.tifac.org.in/]. Accessed February 2003

Publish with Bio Med Central and every scientist can read your work free of charge

"BioMed Central will be the most significant development for disseminating the results of biomedical research in our lifetime. " Sir Paul Nurse, Cancer Research UK

Your research papers will be:

- available free of charge to the entire biomedical community

- peer reviewed and published immediately upon acceptance

- cited in PubMed and archived on PubMed Central

- yours - you keep the copyright

Submit your manuscript here:

http://www.biomedcentral.com/info/publishing_adv.asp
BioMedcentral 